\title{
Iniciativa de creación de una revista
}

¡Buenas tardes!, señora Saray Córdoba, señora Dra. Lastenia Bonilla, directora de la Revista Educación, señora Dra. Alejandrina Mata, decana de esta Facultad; colegas, amigas y amigos todos.

Al pensar en la creación de la revista cuyo aniversario nos reúne hoy, me he planteado dos preguntas clásicas:

1. ¿Cómo se aprende a caminar?

2. ¿Cómo se logra hacer realidad un sueño?

Cada quien lo sabe, porque lo ha vivido, con mayor o menor dificultad.

Diría que, para cualquiera de los dos casos, necesitamos pensar en algo de ayuda externa a nosotros y - como elementos indispensables- hemos de tener un deseo incuestionable de lograr levantarnos y dar los primeros pasos, aunque suframos pequeños traspiés al principio, y también contar con el estímulo de quienes nos animan a intentarlo de nuevo y a no llorar por el golpe

Lo mismo ocurre con la concreción de los sueños. Y, en este segundo caso, si se reúnen más voluntades alrededor de un sueño y se hace una propuesta conjunta, el proceso se vuelve menos difícil.

Desde luego, hay quienes han perseguido y concretado sueños casi solos; pensemos nada más en un ser de ficción que constituye un ejemplo: don Quijote de la Mancha. Él persiguió su sueño imposible y, a pesar de ello, luchó, incansablemente, contra molinos y malandrines para alcanzarlo.

Nuestra revista también estuvo en la categoría de los sueños casi imposibles, pero también hubo Quijotes que lucharon hasta alcanzar su concreción. A pesar de que se sentía la necesidad de contar con un medio de divulgación del quehacer académico, desde años atrás, no había sido posible lograrlo.

Ya en 1976, la llamada Comisión Editorial de la Universidad de Costa Rica -a la que pertenecía el Dr. Mario Fernández Lobo, profesor de la Facultad-, autorizó la creación de la revista, y empezó el proceso de recopilación de artículos y su consiguiente edición.

Don Mario Fernández, en la Presentación del primer número de la revista, afirma lo siguiente: “...sorprende que, en un país como el nuestro, en el que se destinan ingentes recursos a la tarea educativa, haya relativa inopia de publicaciones que permitan reflejar esa realidad cultural. Si bien en el pasado se dieron algunas de, de cierta periodicidad, en el presente tan solo se cuenta con revistas de cultura general que incluyen, entre otras tantas colaboraciones, algunos trabajos específicos de tipo educativo."

Los objetivos de la publicación, como es obvio, debían coincidir con los tres ejes básicos de la Universidad, a saber, la docencia, la investigación y la acción social, y así se enuncian en este primer número de la revista, en la página 3. 
Así, pues, en julio de 1977, vimos nacer y dar sus primeros pasos a la Revista Educación. El sueño se había hecho realidad. Ahora, desde luego, quedaba la tarea seria y responsable, de garantizar que la publicación no terminara "en el tercer número", como se decía en corrillos.

Claro que habían pasado muchos meses en los que, desde los entretelones, se laboraba para recoger los artículos y "levantarlos" en las máquinas de escribir, algunas modernas para esos días, pero limitadas, si las comparamos con los medios que se utilizan actualmente. El proceso para lograr el levantado final era un tanto "primitivo": se hacía una primera impresión que era una especie de "borrador", en el que se señalaban los errores. Entonces, en el taller gráfico, recortaban con un bisturí (o algo similar) la palabra o palabras erróneas, se volvían a escribir a máquina y, recortadas para el tamaño correspondiente, se pegaban en el lugar señalado, para luego seguir el proceso que culminaba con la impresión final. Cierto, habíamos avanzado desde los tipos móviles, pero todavía estábamos en pañales

Durante los primeros años, todo este proceso, que se expresaba así: "Diagramación y diseño; levantado de textos, corrección de pruebas, impresión y encuadernación", se efectuaba en los talleres gráficos de la Editorial Fernández-Arce, propiedad de don Mario y su familia.

Después de pocos años, la impresión de la revista pasa a los talleres de la Editorial de la UCR, aunque don Mario sigue a cargo de la edición.

En sus primeros años, la revista tuvo dos directores: esta servidora durante el año 1977, y el Dr. Jesús Ugalde Víquez de 1978 a 1981. Después tomé yo otra vez la dirección, hasta que me jubilé y concluí mi relación laboral con la Universidad.

El primer Consejo Editorial estuvo integrado de la siguiente manera:

Lic. María Eugenia Dengo de Vargas

Prof. Isaac Felipe Azofeifa

Lic. Jesús Ugalde Víquez

Lic. Yolanda Rojas Rodríguez

Lic. Carlos Moya Barahona.

Más adelante, la integración de ese consejo cambia y, hasta mi retiro, permanece integrado así:

Dr. Albam Brenes Chacón

Dr. Juan Manuel Esquivel Alfaro

Dr. Gerardo Fonseca Retana

Dr. Rafael Ángel Herra Rodríguez

Debo decir que esos años vividos al cuidado de la dirección y la edición de la revista fueron de intenso aprendizaje. La lectura de todos los artículos enviados fue una fuente incomparable, de la que bebí conocimiento y experiencia sobre muchos temas y posiciones sobre ellos; sobre muy variadas y valiosas investigaciones y sobre la creatividad de mis colegas. 
En fin, la revista fue, para mí, cantera de piedras de todos los tipos, con las que fui armando mi mosaico de colores...

Hoy aquellos años parecen y están muy lejanos y solo quedan los recuerdos de una tarea cumplida dentro de la filosofía de "aprender haciendo". No obstante, la edición de la revista no se interrumpió. Ciertamente, hubo atrasos en la publicación y tuvimos que hacer - en algunos años- volúmenes dobles, pero sus pasos siguieron siendo firmes y se sobrepasó, por mucho, el tercer número hasta llegar a los 40 años.

Hoy el panorama es otro. Ha habido muchos cambios y la revista no se imprime en papel. Esa en la tendencia actual. María Elena, la amiga que tanto me guió y me ayudó desde la Oficina de Publicaciones, dice, con voz firme: “TTodo debe ser digital!” Así lo entiendo, pero sigo atesorando mis viejos ejemplares de papel, porque la Revista Educación jahora hay que buscarla en el cielo, en una nube!

Lic. Flor de Ma. Pérez Zamora Ciudad Universitaria Rodrigo Facio Miércoles 28 de setiembre del 2016 